\title{
THE CODIFICATION OF FALSE REFUTATIONS IN ARISTOTLE'S DE SOPHISTICIS ELENCHIS
}

My aim in this paper is to examine the general conception and the detailed problems in Aristotle's comments in the S.E.I on how to organise the handling of false refutations. The influence of Aristotle's work in this area has been immense, as C. L. Hamblin has recently shown: $:^{2}$ the discussions of fallacious and illicit reasoning in books of logic down the centuries are dominated by the aim of adhering to what their authors conceive to be Aristotle's divisions of the subject. Even after the logical and metaphysical bases on which the Aristotelian treatment rests had been abandoned, logicians persisted with a codification of fallacies the very purpose of which had become obscure. Hamblin has well exposed the distortions to which the servile but misconceived tradition has subjected Aristotle's insights. Now that modern developments in formal logic enable us to appreciate that Aristotle's syllogistic occupies a small, albeit paradigmatic, part of the calculus of relations, ${ }^{3}$ we are better placed to understand the character of the non-syllogistic areas of his logical work. At the same time there has been a growth in the historical understanding of Aristotle's dialectic.4 So the way should lie open to a better appreciation of Aristotle's conception of errors in argument, and to a clearer grasp of the actual phenomenon.

Hamblin offers such an essay; but it has failed to convince. ${ }^{5}$ His prescription for a theory of faults in argument turns on the resurrection of the formal dialectical contest, rather than on attending to deviations from the standards set by formal calculi. This feature of his analysis is linked with his historical reading of Aristotle. For he shares the common belief that Aristotle's work on the theory and practice of dialectic represents an earlier phase in the development of his thought, one which was to be succeeded by concentration on the formal theory of the syllogism. ${ }^{6}$ Here is not the place to argue that this estimate of Aristotelian dialectic is badly mistaken. What is important to note is the connection between such an estimate and the theoretical embarrassment betrayed by a number of the logicians who have followed Aristotle in discussing fallacies. ${ }^{7}$ There is a strangeness in the procedure whereby a treatise which

I Reference to this work will be by chapter and Bekker page and line number only.

2 C. L. Hamblin, Fallacies (London, 1970), especially chapters I to 4.

3 G. Patzig, Die aristotelische Syllogistik2 (Göttingen, 1963).

4 Perhaps the soundest available comment is in the Introduction to J. Brunschwig, Aristote: Topiques, Tome I (Paris, 'Les Belles Lettres', 1967). But I must immodestly ask those who wish for a more accurate assessment of this question to await my forthcoming work on Aristotle's concept of dialectic.

5 See the reviews by Martha Kneale, Philosophical Quarterly xxI (1971), 184, and George Englebretsen, Dialogue XII (1973), 153 .

6 Probably the most influential among the many presentations of this view has been that of F. Solmsen, Die Entwicklung der aristotelischen Logik und Rhetorik (Berlin, 1929), especially pp. 70-6.

7 For examples, see Hamblin, Fallacies, p. 13. 
seeks to indicate how to do something should conclude with a chapter on how not to do it; and this is the more awkward in the case of logic, since the author who presents a formal language is able to dictate the course of the activity on which he comments. In the same way it has been felt that when compared with the formal theory of the syllogism, Aristotle's account of dialectical reasoning, and the works in which it is expounded, represent a falling away from standard. Accordingly it is regarded as of secondary importance or, in the spirit of the geneticist analysis, as a product of Aristotle's immaturity.

My examination of the rationale of Aristotle's programme in the $S$. $E$. will be based on the assumption that his views are misrepresented if we divorce dialectic from formal logic. I shall argue that attention must be paid to certain features of his conception of dialectic, and that to understand this programme we must also make full use of the resources of modern logical theory. In this way we shall see how a theory of error in argument can play a proper part in the exposition of logic.

Developing an idea from Plato, Aristotle locates the sophist's concern as being with appearance rather than reality. The distinctive feature of Aristotle's analysis is to see the appearance as attaching to the sophist's argument. ${ }^{\mathrm{I}}$ Such arguments are used with a variety of aims, chief among which is refutation; other aims are ordered in a series of descending importance and represent, I believe, not so much alternative aims of the sophist, co-ordinate with that of refuting, but less satisfactory achievements which might none the less have to be settled for if refutation cannot be effected. ${ }^{2}$

Certain important consequences follow from this initial characterisation of sophistic material. Firstly, Aristotle's dismissal of some argument as apparent betokens confidence in his ability to provide objective determination of the conditions for valid argument; and the parallel claims about refutation indicate a grasp of the basic nature of the principle of non-contradiction, which is put to such crucial use in developing the main theses about quantification, mood and tense in the De Interpretatione. Secondly, the unrestricted scope of the sophist's concern means that the standard of argument from which his deviates is the dialectical. ${ }^{3}$ Each apodeictic science, including the science of general ontology which is prosecuted in the Metaphysics, has its own special field; ${ }^{4}$ and in this field its competence is restricted, by the rules of apodeictic, to proceeding from true first principles by valid reasoning to true conclusions. This is, of course, the apodeictic ideal: in practice error can occur, and we shall see that some sophistic reasoning comes under this head. But the consequence of this specification is that dialectic, and not science, provides the key for the analysis of the ways in which argument can appear to be what in reality it is not.

Later I shall examine Aristotle's detailed comments on the distinctions and connections between the thirteen types of apparent refutation which he diagnoses. But first

I. 164 b $25-165$ a $4 ; 17.175$ a $31-6$.

2 3. 165 b 18-22. At 14. 173 b 23-5 (cf. 32. I 82 a 20-4, 182 b 3-5) Aristotle speaks of 'syllogising solecisms', thereby indicating that arguments which are concerned with solecisms are posterior in definition to syllogisms and refutations simpliciter. On solecisms see further p. $\mathbf{I}$ below.

3 2. 165 b 7-8; 34. 183 a $27-8$.

4 II. I72 a II-I $3 ;$ Met. K3. 106 I 28-b II. 
we should consider some general claims which he makes about his treatment, especially in the important chapters 8 to I I. These chapters follow Aristotle's first run through the thirteen types, which is designed to assist those who would perpetrate them. Later he will appear to rework the same material for the benefit of those who aim to expose such arguments; it is in this second version that most of the potential uncertainties in the classification arise. He can afford the luxury of appearing to vacillate here because he is able to support claims which are advanced in these chapters.

Two themes, which are closely connected, dominate his remarks in this section of the work: the objectiveness and the exhaustiveness of his codification of errors in refutation. In both cases the problems arise from certain features of his concept of dialectic, and insights derived from that concept are used to resolve them.

Aristotle recognises that his characterisation of sophistical refutation as apparent raises the question - apparent to whom? The occurrence of such a refutation depends on someone accepting as a fair move in an argument what is not in fact so. ${ }^{\mathrm{I}}$ Dialectic in general has to recognise the diversity in the intellectual equipment of its participants and audience; this recognition is built into Aristotle's theory of the nature and function of dialectic. ${ }^{2}$ Argument, including the type which conforms with the syllogistic blueprint specified in the Prior Analytics, must reflect the fact that it is offered to convince an audience. ${ }^{3}$ Logic and sophistic thus lie along a continuum: both must move in a way that appears fair, but the distinctive feature of sophistic is that its arguments are arguments only if their elements are accepted by someone.

Aristotle argues that it is not open to a skill to consider what may appear to a chance individual.4 In composing a manual such as the S.E. he must attend to the types of person who might be recipients of the sophist's arguments; and it is clear from parallel contexts where he discusses the subjective element in skills, that the ground for distinguishing the types of person lies in certain features intrinsic to the arguments, rather than in psychological factors which do not relate specifically to arguments. ${ }^{5}$ This requirement emerges from a polemic in chapter 10 which Aristotle conducts against a rival division of sophistic arguments. Evidently, just as it was argued that two categories of things were sufficient where Aristotle needed ten, so here a division into arguments against the name and against the thought was felt to exhaust the field which Aristotle divides into thirteen types. ${ }^{6}$

His reply is that while arguments against the name are a genuine type, arguments against the thought are not. ${ }^{7}$ In fact single names are just one of the features of a language which can mislead us in arguments. But if we ignore this and interpret the division as incorporating all six Aristotelian types of argument based on a language, the distinction between them and arguments against the thought cannot be sustained. An argument which contains an ambiguous word may or may not be against the

I 8. 170 a $12-19$.

2 Top. A :o-11; $\theta_{5}$; see my 'Aristotle on Relativism', Philosophical Quarterly xxIv (1974), esp. p. 202.

3 See Patzig, Syllogistik, chapter 3.

4 9. 170 b $5-8$.

5 Rhet. A2. 1356 b 28-1357 a 7; E.N. A . 1095 a 2-11.

6 10. 170 b 32-5. 7 10. 171 a 23-7. 
thought, depending on how the word is understood by the participants in the debate; or so it may be supposed if a person's understanding of linguistic elements in the argument is to form a basis for classifying it. But Aristotle insists that the ambiguity which an unfair argument exploits is an intrinsic and objective feature of it, not a matter of subjective linguistic experience. ${ }^{I}$ The rival division proposes one spurious type of argument and dilutes the real nature of the other.

This polemic shows that while Aristotle recognises the subjective element in the effectiveness of apparent arguments, he will not allow this to determine the types into which they should be distinguished. Rather, it determines that there should be such types at all. It is not surprising, therefore, that the greater part of chapters 8 to Ir is devoted to the other theme in his general characterisation of sophistic argument, the question of the exhaustiveness of his analysis.

The discussion under this heading falls into two parts. The first, which occupies the bulk of chapter 8, leans heavily on the list of thirteen types of apparent argument which have already been rehearsed. Aristotle argues that if we attend to the definition of reasoning, we can discover how different parts of it may fail to be adhered to, and this will yield the list of errors which he maintains to be exhaustive. ${ }^{2}$ The main burden of the argument, however, does not lie in this cursory analysis, but in his attempt to show that such arguments are sophistical. ${ }^{3}$ The proof is that since these arguments lead to false conclusions, either they will not be seen or they will be seen to do so. If the former, they will be masquerading as dialectical arguments; and if the latter, they will pretend to be testing (peirastic) arguments, the aim of which is to show up the incompetence of one who pretends to scientific expertise, by using argument to force him to admit a falsehood. The relevance of this thesis about peirastic will be examined in a moment. What matters for the argument of chapter 8 is that it is a type of dialectic; 4 and the analysis in this chapter shows that failure to observe one or other of the requirements of correct reasoning produces false conclusions in a way which justifies the claim that such arguments assume the guise of dialectic. This is Aristotle's justification for maintaining the exhaustiveness of his treatment. Sophistic argument trades on two types of false appearance in argument. Both can be produced in just thirteen ways; and the appearance is a mirage of dialectic.

The substantive question that this analysis bequeaths for further investigation is how the sub-peirastic arguments, which are first mentioned in this chapter, are to be related to the straightforwardly sub-dialectical types of argument which appear to be Aristotle's sole concern in chapters 4 to 7 . He pursues this issue in chapters 9 and $\mathrm{I} x$. Here the argument is conducted against the background of a threat to the possibility of any general study of sophistic. Given the existence of a number of diverse scientific skills whose practitioners, in each case, are liable to produce false conclusions in their reasoning, how is such diffuse material to be organised under any single heading for

I Io. 170 b $_{38-40 .}$

2 8. 169 b $37-170$ a 11 .

3 8. 169 b $18-20$.

4 See Christopher Kirwan, Aristotle's Metaphysics Books $\Gamma, \Delta, E$ (Oxford, 1971), pp. 84-5, who is, however, over-cautious about this. To the passages which link dialectic and peirastic add Top. $\theta$ II. I6r a 25. 
the purpose of analysis? 1 This problem is analogous to the one encountered in our discussion of the objectiveness of the analysis, where anarchy threatened once it was allowed that we should take account of the subjects who are deceived by apparent reasoning. There Aristotle used the notion of dialectic, as a practice which individuates the subject participants by means of objective features in the views held by them, to combat an excessively psychologist interpretation of his position. So here dialectic enables him to resist the fragmentation of the study of argument which his own theory of science might suggest.

Aristotle's view of dialectic is that while it covers the territory which is also covered by the special sciences, it does not usurp the role which each science is uniquely fitted to perform. Because the scope of dialectic is general, it is no science. ${ }^{2}$ In the whole scheme of intellectual investigation it has the different function of probing those areas of a special science on which the science itself lacks the facility to pronounce. So it is possible to view the relation between a dialectical and a scientific argument in two ways (and I believe that this duality, rather than any development of doctrine, in large measure explains Aristotle's variously laudatory and pejorative comments on dialectic in different contexts): either the two are seen as different in aim and therefore cognate with one another, or they are seen as covering the same subject-matter and therefore mutually competing to some degree. These two views of dialectic are represented by the distinction drawn here between dialectic and peirastic; and so if sophistic in general is a deviant form of dialectic, we would expect to find its arguments taking a subpeirastic as well as a sub-dialectical guise. ${ }^{3}$ The crucial point is that because of the relation between dialectic and the sciences the same arguments are used in both types of dialectic - that is, whichever view of dialectic is taken. Likewise the same arguments satisfy each of the two descriptions of sophistic, whether it be arguments which only appear to be dialectical or those which only appear to be proper to a particular science.

So it can be shown that all false reasoning which does not occur within the context of the proper pursuit of a science is a departure from the standard of dialectical reasoning. ${ }^{4}$ We can then refer to the abbreviated argument of chapter 8 to show that there are just thirteen possible such departures. Thus the meta-theory of sophistic presented in chapters 8 to II uses the concept of dialectic to sustain its two main theses about the detailed analysis. On the one hand, the fact that sophistic argument is apparent means that we must be concerned with what appears to whom. On the other hand, the subjective side of this formula is controlled by focusing on the reasons why persons are deceived, and the objective side is determined by the existence of a practice which covers all the topics to which the sophists lay claim. Dialectic guarantees the objectiveness and the exhaustiveness of the analysis.

But this is only the meta-theory. We must now examine how satisfactorily the detailed reduction of particular arguments to argument-types meets this general prescription. I propose to examine all of Aristotle's comments on the connections and

I 9. 170 a 20-34.

2 9. 170 a $35-9$; II. I72 a II-b I.

3 II. 17 I b 34-172 a 2, and especially 172 a 9-12.

4 II. 172 b I-8. 
distinctions between the thirteen types. In a number of passages he suggests that certain of the types are subordinate to others; he also rejects attempts to bring arguments under headings different from the ones which he favours. The details of these inquiries into the validity of the general scheme give us our best insight into its nature.

It will be convenient to refer to the argument-types in a way which does not beg questions. So I assign a code to each and describe its nature using the name given by Aristotle rather than by subsequent tradition.

A dependent on the expression

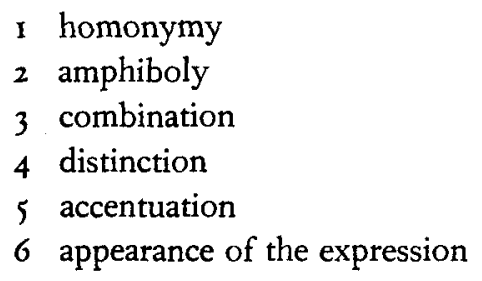

$B$ independent of the expression

I accident

2 qualification

3 misunderstanding of a refutation

4 consequent

5 assuming the original issue

6 positing as a cause what is not a cause

7 making one question out of many questions

Thus I use As to refer to arguments which turn on accentuation, B2 to those which turn on qualification, and so on.

First there are the relations within the two major classes $\mathrm{A}$ and $\mathrm{B}$. As far as $\mathrm{A}$ is concerned, Aristotle's comments on types I to 6 mark their similarities without blurring their differences. A typical comment is on the relation between arguments of types AI and A6. He notes that in both cases the attempted refutations turn on treating the linguistic forms of things as guides to their natures. Such apparent refutations become actual refutations when the respondent endorses these suggestions of surface grammar. ${ }^{1}$ Similarly $\mathrm{A}_{3}$ and $\mathrm{A}_{4}$, which are the reverse of each other, ${ }^{2}$ are examined for their relation to A2, as is $A_{5} .^{3}$ Since $A_{1}$ and $A_{2}$ are treated in the same way, ${ }^{4}$ the scheme with the $A$ arguments and their types is completely worked out. 5

The philosophical character of Aristotle's conception of A arguments will become clearer when we examine the relations between them and some of the B arguments. But we can say now that the distinction between syntax and semantics sits somewhat uneasily with the A classification. A2, 3, 4 and 6 seem to trade on broadly syntactical features of a language, while AI and As relate to semantics. But Aristotle's comments

I 22. 178 a $16-28$.

3 20. 177 a $38-b$ 9.

20. 177 a 35 .

4. 166 a $14-21$.

5 This could provide an argument to back up the claim at 4.165 b $27-30$. 
on the relations between the argument-types do not indicate a recognition of this fundamental distinction in the modern study of languages. I think that he would reply by appealing to his own classification - and in particular the examples of Az and $A 6$ arguments - to contest the fundamental nature which is claimed for the modern distinction. It should be noted that modern analysis of languages has introduced another category, that of pragmatics. ${ }^{I}$ This is the study of that aspect of languages which concerns their use in a context. While its main area of application arises in connection with indexical expressions such as pronouns and other opaque designators, it also cuts across the distinction between syntax and semantics. Aristotle's sophistic arguments should be viewed as occurring in a context, as should the dialectic from which they deviate; so the example of pragmatics provides a parallel for his conception of the $A$ arguments.

The relations between the types of $B$ argument are less thoroughly explored. On one point Aristotle is emphatic: $\mathrm{B}_{4}$ is a sub-type of $\mathrm{Br}$. He makes this point three times in chapters 6 to $8 .^{2}$ Yet also in these chapters he suggests what seems to be an alternative analysis of $\mathrm{B}_{4}$; and this alone is mentioned in chapter 28 , which treats the resolution of $\mathrm{B}_{4}$ arguments. This alternative analysis construes the error as supposing that an implication is reversible. Moreover, after giving the fullest statement of the analysis which assimilates $\mathrm{B}_{4}$ to $\mathrm{BI}_{1}$, Aristotle says that "the matter should be considered in another way too' ${ }^{3}$ Now the basis of this assimilation is that both $\mathrm{BI}_{\mathrm{I}}$ and $\mathrm{B}_{4}$ arguments exploit accidental identities. While $\mathrm{B}_{4}$ must handle more than one object in this way, $\mathrm{BI}_{\mathrm{I}}$ need not: therefore $\mathrm{BI}_{\mathrm{I}}$ is a class of wider scope than $\mathrm{B}_{4}$. The accompanying examples make it clear that what Aristotle has in mind when he talks of a BI argument handling a single object is a shift between different designations of an object, among which at least some are referentially opaque. The key notion in the analysis of $\mathrm{Br}$ arguments is the non-substitutability, across different contexts, of certain modes of reference. 4 The $\mathrm{B}_{4}$ arguments are concerned with these matters where a number of properties are mentioned. These too may be referentially transparent or opaque in the way they designate objects; and this is reflected in Aristotle's comment that in such a case more than one object is involved, a comment which others would gloss as saying that more than one property-designation is referentially opaque. 5

So the distinction between $\mathrm{B}_{4}$ and $\mathrm{BI}_{\mathrm{I}}$ arguments can be interpreted as meaning that the former are marked off by concentrating on accidental property-identities ${ }^{6}$ and then we can better understand Aristotle's inclination to offer an alternative analysis of

I See Robert C. Stalnaker, 'Pragmatics', in Semantics of natural languages, edd. D. Davidson and G. Harman (Dordrecht, 1972), pp. $380-97$.

26. 168 b $27-31 ; 7.169$ b 6-7;8. 170 a 4-5.

36.169 a 5 .

4 See W. V. Quine, From a logical point of view2 (Cambridge, Mass., 1961), pp. 139-59.

$5 \mathrm{My}$ purpose in using this unaristotelian language is to show how a modern exponent of the distinction between contexts of reference would comment on the syllogistic, which he would probably interpret as talking about properties. Aristotle's different way of describing these matters follows from his distinction between essence and accident.

6 See John Heintz, 'Property existence and identity', Journal of Philosophy Lxx (1973), 734 43, esp. 738-9. 
$\mathrm{B}_{4}$ in terms of the non-reversibility of implications. This would provide a serviceable tool for the resolution of such arguments. But it does not explain that aspect of their logic which in Aristotle's view makes people liable to be seduced by them. The crucial point to emerge from ranging $\mathrm{B}_{4}$ with $\mathrm{BI}$ arguments is that the essentialist will want to utilise the distinction between transparency and opacity of reference not only in his treatment of the designation of particulars but also in his handling of properties and classes.

This discussion has a more general lesson. The alternative analysis of $\mathrm{B}_{4}$ arguments has been regarded by some ${ }^{1}$ as a precursor of the more formal treatment of invalid reasoning which Aristotle will be able to present in the Prior Analytics and which is still generally unavailable to him at the period of the S.E. Against this it may be observed that Aristotle is always hostile to the idea that accidental connections could be the object of reasoning. ${ }^{2}$ The analysis of $\mathrm{B}_{4}$ as subordinate to $\mathrm{Br}$ shows that the formal theory of reasoning is philosophically grounded in essentialism.

One other passage examines connections between B argument-types. In chapter 24, which is devoted to the resolution of $\mathrm{Br}$ arguments, Aristotle first diagnoses their fundamental error as assuming all entities to be essentially unitary. ${ }^{3}$ Then he proceeds to reject certain alternative lines of resolution. The first of these proposes that some arguments, which Aristotle brings under the Br heading, can be resolved by the specification of qualifications. Thus the apparent contradiction in the claim that someone knows and does not know the approaching Coriscus can be eliminated, on this suggestion, by distinguishing the respects in which Coriscus is apprehended. ${ }^{4}$ Aristotle's favoured analysis turns rather on the distinction between the essential and the accidental descriptions under which Coriscus can be identified. The objection to the alternative analysis is firstly that it will not provide an instrument for resolving all $\mathrm{BI}_{\mathrm{I}}$ arguments, which is a requirement upon the genuine key, ${ }^{5}$ and secondly that it can be contested even in the case for which it is presented. For the problem with the approaching Coriscus arises precisely because one knows both Coriscus and the approaching thing in the same respect - namely that each respectively is what it is. ${ }^{6}$

It is tempting to construe the rejected analysis as proposing that these arguments should be brought under the heading B2, since it exploits the qualifications which can attach to things. I think that this is wrong. The central philosophical element in the arguments which are gathered under $\mathrm{B}_{2}$ is that they involve difficulties of selfreference. In their sharpest form they relate to cases where a concept operates upon its own contrary; and the value of invoking the distinction between unqualified and qualified forms of a concept lies in unravelling the ensuing problems of scope.7 Knowledge about ignorance would be an example of the sort of difficulty which can arise here. But the disputed $\mathrm{B}_{1}$ arguments are not of this type. In fact $\mathrm{B}_{3}$, rather than B2, seems to be the heading under which the rejected analysis would bring these

1 Gilbert Ryle, Plato's progress (Cambridge, 1966), p. I43; Hamblin, Fallacies, p. 86.

${ }_{2}$ Met. E2;An. Pr. A I 323 b 19;An. Post. B 30 . All syllogistic requires at least one universal premiss.

3 24. 179 a $35-9$.

4. 179 b $7-11$.

5 24. 179 b $15-21$.

6 24. 179 b $27-33$.

725.180 a $32-b 6$. 
arguments. The nature of type $B_{3}$ is problematic, as we shall see. But the examples which Aristotle brings under it can be seen to have in common a failure to observe one of the stipulations - holding in the same respect, in the same relation, etc. - which are specified in the full statement of the principle of non-contradiction. This is the type of analysis which is rejected as a resolution of certain BI arguments in chapter $24 .^{\mathrm{I}}$

I turn now to passages that examine the relations across the distinction between types A and B. This is the fundamental distinction in Aristotle's analysis; so his whole scheme is put under its greatest threat by the alternative analyses which we shall now see him reject. First we find an alternative analysis of $\mathrm{A}_{3}$ and $\mathrm{A}_{4}$ arguments, ${ }^{2}$ which in Aristotle's view involve issues of the scope of elements in sentences. The alternative is, as in the previous case, debatably $\mathrm{B}_{2}$ or $\mathrm{B}_{3}$ : it suggests that if we specify qualifications, it will be possible to avoid the contradiction which Aristotle believes to come from a misunderstanding of syntax. Here again $I$ think that the rejected analysis fits the pattern of $\mathrm{B}_{3}$ rather than $\mathrm{B}_{2}$.

Then there are a number of passages that propose an $A_{1}$ or A2 analysis for arguments which Aristotle places under a $B$ heading: the integrity of the groupings $\mathrm{Br}$, $\mathrm{B}_{2}$ and $\mathrm{B}_{7}$ is thus put in doubt. So the expression which gives an accidental identity may be construed as ambiguous between this sense and that according to which it signifies an essential identity. ${ }^{3} \mathrm{~B}_{7}$ arguments, where two subjects are treated as a single subject of predication, may be interpreted as resolvable by exposing ambiguities in their quantificational devices - that is, in their use of such words as 'all' or 'both'.4 With B2 arguments the rejected analysis takes the reverse course of proposing that arguments involving ambiguities should be construed as reducing objects to object-aspects. ${ }^{5}$ It may be questioned even here, in the absence of any explicit indication from Aristotle, whether $\mathrm{B}_{2}$ - rather than $\mathrm{B}_{3}$ or perhaps $\mathrm{BI}_{1}$ - is the pigeon-hole which he is thinking of. But since elsewhere he makes crucial use of the B2 distinction to combat reductionist theses, ${ }^{6}$ this is probably the heading under which he would bring the rejected analysis of ambiguities. What is most significant is that here we find rejected a proposal to analyse ambiguities in terms of the nonlinguistic device of a theory about objects.

Aristotle opposes these attempts to locate such types of error in features of the language. His reason is that these are faults which can occur in any language and are

I The example of a $\mathrm{B}_{3}$ argument at 26 . 181 a $8-1$ i strongly recalls the disputed argument at 24. 179 b 7-I I.

2 20. 177 b 27-34.

3 24. 179 b 37-180 a 22.

${ }_{4} 30$. 181 b 19-24. On the other hand the comparison of $A_{1}$ and $B_{7}$ at 17.175 b 39-176 a 18 has no tendency to undermine the $A / B$ distinction.

5 17. 175 b 18-27. This obscure passage examines an escape route from the argument that the reference of an ambiguous name is determined by whatever makes true a statement in which it occurs. The suggestion contests this argument by maintaining that while the object of reference is fixed, the object-aspect ('this Coriscus') is not. Aristotle thinks that this suggestion concedes too much, and appeals to the case of visible objects - viz. those where the definiteness of reference of the name is uncontestable.

${ }^{6}$ The prime context is the discussion of the object of wish in E.N. $\Gamma_{4}$. See "Aristotle on Relativism', pp. 198-9, and an extended treatment in my forthcoming work on dialectic referred to above. 
specific to none. Of course, the arguments in which they occur must be presented in a language; in this case the particular language is Greek. This means that the language in which a particular argument is couched may suggest that it should be faulted under the heading of one of the A argument-types. But this diagnosis can be contested because it will not resolve other arguments which clearly depend on the same fault. If this procedure, which is Aristotle's most powerful tool in his exploration of the relations between the various types of argument, seems to beg the question, his reply would be that in classification there is no short cut which will eliminate the need to explore one's intuitions concerning the groupings into which the individual entitiesarguments in this case - fall. ${ }^{\mathrm{T}}$ This is what he does in the passages under discussion.

The distinction between A and B types of argument is subtle and fundamental. We should contrast what Aristotle says about the relation between A6 refutations and solecisms: here he suggests that since a man is both a thing and a name, a simpleminded view about the ability of names to retain their identity through inflectionary change may be compared with a like view about the ability of things to maintain their identity through change in the grammatical type of their names. ${ }^{2}$ The crude confusion of mention and use which this comment suggests should not mislead us since Aristotle is clear that solecisms are radically different from refutations. But those who follow Aristotle in not recognising a deep structure of language underlying the surfaces along which normal discourse in actual languages proceeds, ${ }^{3}$ will not find any similarly simple device for distinguishing A from B arguments. Once again pragmatics is the notion which modern analysis most suitably presents as a parallel for Aristotle's conception of a dialectical activity. For this notion provides a counter to those abstractions which divorce the study of languages from the study of things, or the form of sentences from that which gives them meaning; and this matches the conception of dialectic as the method of grasping things through the linguistic mirror in which philosophical arguments present themselves to us. ${ }^{4}$

This needs to be borne in mind when we consider one final set of comments on the relation between some $A$ and $B$ arguments. After giving his first analysis of $B_{3}$ arguments, Aristotle notes that they might be brought under the A heading. ${ }^{5}$ But in the next chapter he systematically explores the suggestion that all apparent refutations are of type $B_{3}$. The reason behind the latter suggestion is that $B_{3}$ arguments turn on the details of the principle of non-contradiction and this principle is the basis of all reasoning and refutation: hence we should not be surprised that all deviant argument can be faulted on this score. But Aristotle is right in thinking that this does not obviate the need for the other groupings which he recognises. His comments on the

I For a parallel conception of method in zoological classification, see D. M. Balme, Aristotle's De Partibus Animalium I and De Generatione Animalium I (Oxford, 1972), p. 105.

2 I4. I 74 a $5 \rightarrow 9$.

3 For this reason I treat 'language' as a count-noun, always speaking of 'a language' when I gloss Aristotle's views. The use of 'language' as a mass-noun tends to beg the question in favour of deep structure.

4 For a sound treatment of Aristotle's ideas on the relation between the investigation of words and things, see Renford Bambrough, 'Aristotle on justice: a paradigm of philosophy', in $N e w$ essays on Plato and Aristotle, ed. Renford Bambrough (London, 1965), pp. 159-74.

5 . 167 a 35 . 
suggested reduction of $B_{2}$ to $B_{3}$ (whose close connection we have already noted) are instructive. That 'simply $F$ ' is the predicate which contradicts 'simply not- $F$ ', ${ }^{1}$ is an application of the principle of non-contradiction which will be grasped only by one who already has a sense of the distinctive character of $\mathrm{B}_{2}$ arguments. As for the suggestion that $\mathrm{B}_{3}$ arguments are resolvable by linguistic considerations, this perhaps arises from the idea that it would be possible to construct a language which, by making explicit all qualifications, would render perspicuous any failure to achieve a genuine contradiction. This idea holds great attraction for philosophers of logic and is an important ingredient in the critical belief that what Aristotle treats in the S.E. does not belong with formal logic. But Aristotle does not seem to have any such view of the nature of a formal system; he would comment that such an ideal for a language is a distortion of the true asymmetry in the relation between words and things. ${ }^{2}$

We have examined each of the detailed comments in the S.E. on the connections between the different types of apparent argument. These should be read in conjunction with a general observation on the task of codifying such arguments: ${ }^{3}$

One should also realise that in the totality of arguments with some it is easier and with others more difficult to see why and in what respect they cause the audience to reason badly, these often being the same arguments. For one should call 'the same argument' that which is due to the same factor. The same argument might seem to some to be due to the expression, to others to be due to the accident, and to others to be due to something else, because as each of these undergoes transformations it is not equally clear.

The material is complex and diffuse. Yet Aristotle is convinced that it can be ordered into a scheme that is both objective and exhaustive. As we have followed the detailed support for these claims, we have seen how it raises questions which are of basic and continuing concern to the philosophy of logic.

SIDNEY SUSSEX COLLEGE, CAMBRIDGE

J. D. G. EVANS

I $6.168 \mathrm{~b} \mathrm{xi-16.}$

2 I. 165 a 6-13.

3 33. 182 b 6-12. 